\title{
Seroprevalence of hepatitis $C$ in type 2 diabetes: evidence for a positive association
}

\author{
Nauman A Jadoon*, Mohammad A Shahzad, Rehan Yaqoob, Mansoor Hussain, Naseema Ali
}

\begin{abstract}
Background: There is a growing body of literature on the relationship of Hepatitis $\mathrm{C}$ virus infection (HCV) and type 2 diabetes mellitus (T2DM). However, there are certain gaps in literature and the data is inconclusive. This study was, therefore, carried out to determine the prevalence of HCV infection in diabetic patients and to elucidate the presence of any possible relationship between HCV and T2DM in this region.

Methods: Serologic testing for anti-HCV antibody was done on a sample of 3000 individuals with T2DM visiting Diabetes Clinic of Nishtar Medical College Hospital, Multan and 10,000 volunteer blood donors visiting blood bank of the same hospital during the study period using Accurate rapid immunochromatographic kits which was later confirmed by using Chemelex S.A third generation ELISA kit for positive cases. Data about various variables was collected from diabetic patients using a structured questionnaire after taking informed consent.
\end{abstract}

Results: Prevalence rate of $13.7 \%$ for HCV infection was recorded among subjects having T2DM with seropositivity rate of $4.9 \%$ among the control group of volunteer blood donors without diabetes. The patients with T2DM were more likely to have HCV infection as compared to the control group ( $\mathrm{OR}=3.03,95 \% \mathrm{Cl}=2.64-3.48, \mathrm{p}=0.001)$. Diabetic patients with age above 55 years had higher prevalence rate as compared to younger individuals. Male patients had significantly high seropositivity as compared to female patients ( $15.3 \%$ vs. $12.4 \%, p=0.02$ ). Those with duration of diabetes 11 years and above and the ones with good glycemic control had higher seroprevalence rates of $18.2 \%$ and $18.7 \%$ respectively. There was no statistically significant difference among subjects when the distribution of HCV was studied on the basis of marital status, locality, or family history of diabetes.

Conclusions: The results show that there is a strong association between HCV and T2DM in the region as evident from significantly higher prevalence of HCV infection in diabetics as compared to the control group in the present study.

\section{Background}

Hepatitis $\mathrm{C}$ virus (HCV) infection is an important public health problem which currently affects more than 170 million people (about $3 \%$ of world population) out of which $55-80 \%$ have chronic infection [1]. It is a common cause of acute and chronic hepatitis accounting for about half of all the cases of CLD in USA [2]. The likelihood of chronicity after acute HCV infection is as high as $85 \%$ with chronic infection being common even in those having normal aminotransferase levels after the acute episode [3]. The progression to cirrhosis is up to $50 \%$ even in well compensated patients. The incidence of $\mathrm{HCC}$ in patients with cirrhosis ranges from $1-4 \%$,

\footnotetext{
* Correspondence: dr.naumanjadoon@gmail.com

Department of Medicine, Nishtar Medical College Hospital, Multan, Pakistan
}

most cases comprising of patients with $\mathrm{HCV}$ infection duration exceeding 30 years [3]. The severity and rate of progression depend on several disease related factors and various host related factors [3,4]. Infection with HCV has been shown to produce both hepatic and extrahepatic manifestations, the latter including insulin resistance, essential mixed cryoglobulinemia, glomerulonephritis, porphyria cutaneous tarda and benign monoclonal gammopathy [5,6]. A meta-analysis showed that $\mathrm{HCV}$ increases the risk of type 2 diabetes mellitus (T2DM) by 1.8 times in excess of that posed by relative degree of liver pathology [7].

The link between the $\mathrm{HCV}$ and diabetes was first reported by Allison et al. in 1994 and later explored by Simo and colleagues in 1996 [8,9]. The initial idea that patients with T2DM have more parenteral exposures
C Biomed Central 
because of use of finger stick devices and thus are at an increased risk of contacting blood borne infections such as HCV was disproved by a study from France in 1998 [10]. The epidemiological link between T2DM and HCV has been investigated from two perspectives. Various studies have shown high HCV seropositivity among patients with T2DM as compared to the control group, prevalence being two to seven times higher in the diabetic group [11-14]. However, other investagators performing did not find such an association of HCV with T2DM [15-17]. In addition, several studies have shown that HCV increases the risk of development of T2DM [7]. The mechanism of pathogenesis of diabetes in patients with $\mathrm{HCV}$ infection remains unclear though it has been implicated that insulin resistance plays an important role and is related to fibrosis score [18-20]. After controlling for potential confounders, Mehta et al. reported that $\mathrm{HCV}$ infected individuals were 3.77 times more likely $(95 \% \mathrm{CI}=1.80-.87)$ to have $\mathrm{T} 2 \mathrm{DM}$ as compared to those without the infection [21].

Pakistan is in the intermediate HCV prevalence area with approximately 10 million people infected predominately with genotype 3 based on an average prevalence rate of $6 \%$. The prevalence ranges from $3-4 \%$ in volunteer blood donors according to a meta analysis. About $60-70 \%$ of the patients with CLD and half of the ones with HCC in the country have HCV infection [22]. Diabetes has become an important public health problem in Pakistan with 7.1 million diabetics in 2010 expected to rise to 13.8 million in 2030 when the country will rank fourth in terms of number of patients aged 20-79 with diabetes [23]

Although there is a growing body of literature on the link between T2DM and HCV, the studies are contradictory and the data is inconclusive [11,13-17,24-30]. Secondly, it is not known if diabetes is a risk factor for the development of HCV. The study will be valuable in this regard. Moreover, there is paucity of studies on the subject from Pakistan with no study being from this region to the best of our knowledge [12,31]. In addition, the previous studies from Pakistan employed a small sample size with no control group [12,31]. The present study will thus be important in elucidating any relationship between HCV and T2DM in the region. In addition, it is necessary to determine the prevalence of $\mathrm{HCV}$ among diabetics to increase awareness among general population and health care workers to prevent morbidity and increased costs associated with this infection in diabetes due to failure of treatment [24]. Since the prevalence of diabetes is on the rise and is complicated by coinfection with $\mathrm{HCV}$, the determination of relationship becomes even more important in this scenario so that it can be effectively managed $[23,24]$. Furthermore, the study is supposed to provide valuable insight regarding usefulness of focused screening program in T2DM as effective therapies have evolved for $\mathrm{HCV}$ which may prevent complications caused by $\mathrm{HCV}$ in this subgroup.

The objective of this study was to determine the prevalence of $\mathrm{HCV}$ in patients with T2DM and to elucidate the presence of association between HCV and T2DM by comparing seropositivity rates in diabetic patients with a control group comprising of healthy volunteer blood donors from the same area. Data was also analyzed for the presence of difference among various groups with respect to various variables after dividing patients into two groups on basis of HCV infection status.

\section{Methods}

\section{Participants}

The study was carried out on a sample of 3000 consecutive persons with confirmed type 2 diabetes visiting Diabetes clinic at Nishtar Medical College Hospital, Multan for follow up. Subjects were excluded if they had type 1 diabetes, were transplant recipients, emergency cases or dialysis patients. A control group comprising of healthy blood donors were taken from the same hospital who visited the blood bank during the study period. Controls were excluded from the study if they had diabetes. Ethical clearance for the study was obtained from the Ethics Review Committee of hospital.

\section{Sample Collection and Antibody Detection}

Sample collection was carried out using sterile needle and syringes which were transferred to the lab for analysis. $3 \mathrm{ml}$ of peripheral blood was obtained via venepuncture for each subject. The blood was centrifuged and sera were stored in dry clean sterile containers at -20C prior to use. Serological analysis for the detection of anti-HCV antibodies was carried out using Accurate rapid immunochromatographic kits. Positive cases were later confirmed by using third generation ELISA kit (Labkit Chemelex, S.A., Barcelona, Spain) for qualitative detection of anti-HCV antibodies.

\section{Data Collection}

After explaining the purpose of the study, written informed consent was taken from the participants before collecting data and taking samples. Data was collected using a structured questionnaire containing questions related to demographic and clinical characteristics of patients.

\section{Statistical Analysis}

Data analysis was carried out using SPSS software. Descriptive analysis was performed and the results were expressed as means and percentages. Odds ratio (OR) and their respective 95\% confidence intervals (CI) were calculated. Pearson chi-square test was used to 
determine the difference among various categories with respect to HCV seropositivity. A p value of $<0.05$ was considered statistically significant.

\section{Results}

The study population comprised of 3000 patients with diabetes and 10,000 controls recruited from the blood bank. The mean age of diabetes patients was $48.19 \pm$ 10.32 years and the mean duration of diabetes was 6.26 \pm 5.50 years. Majority of patients with T2DM were female $(55.7 \%)$ and in the age group $36-45$ years (34.7\%). Most of the cases were married (94.8\%) and were from urban localities (71.8\%). Family history of diabetes was present in only $19.5 \%$ of the participants with majority of participants having poor glycemic control (75.2\%). Description of the study group is outlined in table 1 . The controls were predominantly males with a median age of 27 years.

Screening for the presence of anti-HCV antibody was positive in $906(6.97 \%)$ patients in the entire study group. The seroprevalance was $13.7 \%$ in patients with T2DM as compared to the control group in whom

Table 1 Description of the study group $(n=3000)$

\begin{tabular}{|c|c|c|}
\hline \multirow[b]{2}{*}{ Variables } & \multicolumn{2}{|c|}{ Diabetes Group } \\
\hline & $\mathbf{N}$ & $\%$ \\
\hline \multicolumn{3}{|l|}{ Age } \\
\hline$\leq 35$ Years & 360 & 12.0 \\
\hline $36-45$ Years & 1042 & 34.7 \\
\hline $46-55$ Years & 933 & 31.1 \\
\hline$>55$ Years & 665 & 22.2 \\
\hline \multicolumn{3}{|l|}{ Gender } \\
\hline Male & 1330 & 44.3 \\
\hline Female & 1670 & 55.7 \\
\hline \multicolumn{3}{|c|}{ Marital Status } \\
\hline Unarried & 157 & 5.2 \\
\hline Married & 2843 & 94.8 \\
\hline \multicolumn{3}{|l|}{ Locality } \\
\hline Urban & 2154 & 71.8 \\
\hline Rural & 846 & 28.2 \\
\hline \multicolumn{3}{|c|}{ Duration of Diabetes } \\
\hline $1-5$ Years & 1653 & 55.1 \\
\hline 6-10 Years & 855 & 28.5 \\
\hline$>11$ Years & 492 & 16.4 \\
\hline \multicolumn{3}{|c|}{ Family History of Diabetes } \\
\hline Yes & 2414 & 80.5 \\
\hline No & 586 & 19.5 \\
\hline \multicolumn{3}{|c|}{ Glycemic Control } \\
\hline Good & 744 & 24.8 \\
\hline $\mathrm{Bad}$ & 2256 & 75.2 \\
\hline
\end{tabular}

prevalence rate was $4.9 \%$. Analysis revealed that diabetic patients had significantly higher prevalence of $\mathrm{HCV}$ infection as compared to the control group $(\mathrm{OR}=3.03$, $95 \% \mathrm{CI}=2.64-3.48, \mathrm{p}=0.001$ ).

The distribution of $\mathrm{HCV}$ infection in diabetic patients was then studied with respect to age, gender, marital status, locality, family history of diabetes, duration of diabetes and glycemic control. The results of analysis are presented in table 2. Patients older than 55 years, male patients, having duration of diabetes more than 11 years and the ones with good glycemic control were seen to be have significantly higher seropositive rates of $\mathrm{HCV}$ infection as compared to other groups in respective categories $(\mathrm{p}<0.05)$. It was found that categories with respect to marital status, locality and family history of diabetes recorded no significant difference in seroprevalence among themselves $(p>0.05)$.

\section{Discussion}

In the present study, we found high prevalence of $\mathrm{HCV}$ infection in patients with T2DM as compared to the control group comprising of healthy volunteer blood donors (13.7\% vs. $4.9 \%)$. The results of our study are in agreement with those of some studies conducted earlier in other countries $[7,11,13,14,25,27,28,31]$. The findings also agree with another study conducted earlier in the country albeit with a small sample use and no control group who recorded prevalence of $36 \%$ among diabetics [31]. This is thus the first study to the best of our knowledge in the country which employs a large sample comprising of consecutive patients compared with control group of consecutive blood donors. Furthermore, the prevalence of $4.9 \%$ in blood donors in our study is comparable to earlier studies from Pakistan [22]. The study thus establishes presence of T2DM as a risk factor for $\mathrm{HCV}$ infection in this region.

It was observed that older patients were more likely to have HCV infection as compared to those in the younger age groups $[11,20,21,25,28]$. The high seropositivity recorded in older group may be because of more parenteral exposures as compared to younger people and thus greater chances of transmission of infection.

Analysis of $\mathrm{HCV}$ seropositivity rates with respect to gender revealed that males had higher HCV infection rate of $15.3 \%$ as compared to females in whom prevalence rate of $12.4 \%$ was found. This agrees with the work of Caronia et al. who observed that male diabetics are more likely to contact $\mathrm{HCV}$ infections as compared to females [32]. A significant difference was also observed among patients with T2DM with respect to duration of diabetes. In relation to glycemic control, it was seen that patients with good glycemic control were significantly more at risk of having $\mathrm{HCV}$ infection as compared to those with poor glycemic control. This 
Table 2 Distribution of HCV pattern in diabetic patients $(n=3000)$

\begin{tabular}{|c|c|c|c|c|c|}
\hline \multirow[b]{2}{*}{ Variables } & \multicolumn{2}{|c|}{ HCV Status } & \multirow[b]{2}{*}{ OR } & \multirow[b]{2}{*}{$95 \% \mathrm{Cl}$} & \multirow[b]{2}{*}{$P$ value } \\
\hline & $\begin{array}{c}\text { Positive } \\
\text { n(\%) }\end{array}$ & $\begin{array}{c}\text { Negative } \\
\mathrm{n}(\%)\end{array}$ & & & \\
\hline Age & & & & & .001 \\
\hline$\leq 35$ Years & $38(10.6 \%)$ & $322(89.4 \%)$ & - & - & \\
\hline $36-45$ Years & $103(9.9 \%)$ & 939 (90.1\%) & 0.93 & $0.63-1.38$ & \\
\hline 46-55 Years & $101(10.8 \%)$ & $832(89.2 \%)$ & 1.03 & $0.69-1.53$ & \\
\hline$>55$ Years & $168(25.3 \%)$ & $497(74.7 \%)$ & 2.86 & $1.96-4.18$ & \\
\hline Gender & & & & & .023 \\
\hline Male & $203(15.3 \%)$ & $1127(84.7 \%)$ & - & - & \\
\hline Female & $207(12.4 \%)$ & $1463(87.6 \%)$ & 0.79 & $0.64-0.97$ & \\
\hline Marital Status & & & & & .075 \\
\hline Unmarried & 14 (8.9\%) & $143(91.1 \%)$ & - & - & \\
\hline Married & $396(13.9 \%)$ & $2447(86.1 \%)$ & 1.66 & $0.95-2.89$ & \\
\hline Locality & & & & & .184 \\
\hline Urban & $323(15.0 \%)$ & $1831(85.9 \%)$ & - & - & \\
\hline Rural & $109(12.9 \%)$ & $737(87.1 \%)$ & 0.84 & $0.66-1.06$ & \\
\hline Duration of Diabetes & & & & & .040 \\
\hline 1-5 Years & $231(14.0 \%)$ & $1422(86.0 \%)$ & - & - & \\
\hline 6-10 Years & $107(12.5 \%)$ & $748(87.5 \%)$ & 0.88 & $0.69-1.13$ & \\
\hline$>11$ Years & $90(18.3 \%)$ & $402(81.7 \%)$ & 1.38 & $1.05-1.80$ & \\
\hline Family History of Diabetes & & & & & .143 \\
\hline Yes & $319(13.2 \%)$ & $2095(86.8 \%)$ & - & - & \\
\hline No & $91(15.5 \%)$ & $495(84.5 \%)$ & 1.21 & $0.94-1.55$ & \\
\hline Glycemic Control & & & & & .001 \\
\hline Good & $139(18.7 \%)$ & $605(81.3 \%)$ & - & - & \\
\hline $\mathrm{Bad}$ & $268(11.9 \%)$ & $1988(88.1 \%)$ & 0.59 & $0.47-0.73$ & \\
\hline
\end{tabular}

may be because of various confounding factors and warrants further investigation.

We did not observed any difference in the HCV distribution in study population with respect to marital status, place of residence of participants and family history of diabetes. Our findings regarding family history of diabetes differ from those of an earlier study from Nigeria [25]. The difference may be explained by the difference in proportion of patients with family history of diabetes (19.5\% vs. $8.3 \%)$ and the difference in epidemiology of diabetes and HCV between the two countries.

The study has certain strength as well as same limitations. The study has relatively large sample size as compared to most of earlier studies and enrolled consecutive patients thus reducing recruitment bias and increasing generalizability of findings to a greater population. Secondly, the study used a control group for comparison of findings with the diabetic group. The control group was recruited from the same area as the cases. Furthermore, the study is first of its kind from the region and the first large scale controlled study from a country with a high number of patients with diabetes in which coinfection with HCV can have important implications. The study also has some limitations. We do not have the data on some of the potential confounding factors like exposure to risk factors such as blood transfusion. Moreover, we were not able to confirm the results of screening by using polymerase chain reaction to detect $\mathrm{HCV}$ RNA due to financial and technical constraints. Also we did not study liver enzyme levels in diabetic patients and controls.

The study has some important implications. The increased risk of HCV infection in patients with T2DM warrants screening diabetes person for HCV. Secondly, the study adds to the limited data on the subject available in this region and will help in increasing awareness regarding association of $\mathrm{HCV}$ and diabetes which will help in reducing morbidity and cost associated with this comorbidity in the long run. Prospective, multicentre studies are needed to establish temporal association, 
elucidate the reasons of association as well as the mechanism and determination of other aspects of the relationships.

\section{Conclusions}

In conclusion, there is a significant association between Hepatitis $C$ virus infection and type 2 diabetes in the region according to the findings of the present study. However, it remains to be seen whether diabetes is a risk factor for the $\mathrm{HCV}$ infection or vice versa. It is also evident that certain factors including older age, male gender, longer duration of diabetes and good glycemic control significantly increase the risk of having $\mathrm{HCV}$ infection which warrants special attention to patients with these risk factors. It is important that health care workers pay attention to prompt diagnosis and management of the condition in affected diabetic patients. Further investigation into the association of the two conditions is needed and may elucidate the temporal relationship and improved management strategies.

\section{List of Abbreviations}

CLD: Chronic Liver Disease; HCC: Hepatocellular Carcinoma; HCV: Hepatitis C Virus Infection; ELISA: Enzyme Linked Immunosorbent Assay; T2DM: Type 2 Diabetes Mellitus

\section{Authors' contributions}

NAJ conceived of the study and designed it, participated in data collection, coordinated the study, performed the statistical analysis and interpretation of data, prepared the draft of manuscript and reviewed it. MAS participated in design of the study, carried out data collection and participated in data analysis and reviewed the manuscript. RY participated in design of the study, carried out data collection and participated in data analysis. $\mathrm{MH}$ participated in data collection and analysis and reviewed the manuscript. NA participated in data collection and analysis. All the authors have read and approved the final manuscript.

\section{Competing interests}

The authors declare that they have no competing interests.

Received: 10 September 2010 Accepted: 5 November 2010 Published: 5 November 2010

\section{References}

1. NIH Consensus Statement on Management of Hepatitis C: 2002. NIH Consens State Sci Statements 2002, 19(3):1-46.

2. Kumar V, Abbas AK, Fausto N, Aster J, eds: Robbins and Cotran Pathologic Basis of Disease. 8 edition. China: Elsevier; 2010

3. Fauci AS, Braunwald E, Kasper DL, Hauser SL, Longo DL, Jameson JL, Loscalzo J, eds: Harrison's Principles of Internal Medicine. 17 edition. New York: McGraw-Hill Professional; 2008.

4. Asselah T, Rubbia-Brandt L, Marcellin P, Negro F: Steatosis in chronic hepatitis C: why does it really matter? Gut 2006, 55:123-130.

5. Andreone P, Gramenzi A, Cursaro C, Benardi M, Zignego AL: Monoclonal gammopathy in patients with chronic hepatitis $C$ virus infection. Blood 1996, 88:1122.

6. Zignego AL, Ferri C, Pileri SA, Caini P, Bianchi FB: Extrahepatic manifestations of Hepatitis $C$ Virus infection: a general overview and guidelines for a clinical approach. Dig Liver Dis 2007, 39:2-17.

7. White DL, Ratziu V, El-Serag HB: Hepatitis C infection and risk of diabetes: a systematic review and meta-analysis. J Hepatol 2008, 49:831-844.
8. Allison ME, Wreghitt T, Palmer CR, Alexander GJ: Evidence for a link between hepatitis $C$ virus infection and diabetes mellitus in a cirrhotic population. J Hepatol 1994, 21:1135-1139.

9. Simo R, Hernandez C, Genesca J, Jardi R, Mesa J: High prevalence of hepatitis C virus infection in diabetic patients. Diabetes Care 1996, 19:998-1000.

10. Rudoni S, Petit JM, Bour JB, Aho LS, Castaneda A, Vaillant G, Verges B, Brun JM: HCV infection and diabetes mellitus: influence of the use of finger stick devices on nosocomial transmission. Diabetes Metab 1999, 25:502-505.

11. Mason AL, Lau JY, Hoang N, Qian K, Alexander GJ, Xu L, Guo L, Jacob S, Regenstein FG, Zimmerman R, Everhart JE, Wasserfall C, Maclaren NK, Perrillo RP: Association of diabetes mellitus and chronic hepatitis $C$ virus infection. Hepatology 1999, 29:328-333.

12. Qureshi H, Ahsan T, Mujeeb SA, Jawad F, Mehdi I, Ahmed W, Alam SE: Diabetes mellitus is equally frequent in chronic HCV and HBV infection. $J$ Pak Med Assoc 2002, 52:280-283.

13. Okan V, Araz M, Aktaran S, Karsligil T, Meram I, Bayraktaroglu Z, Demirci F: Increased frequency of HCV but not HBV infection in type 2 diabetic patients in Turkey. Int I Clin Pract 2002, 56:175-177.

14. Chen HF, Li CY, Chen P, See TT, Lee HY: Seroprevalence of hepatitis B and C in type 2 diabetic patients. J Chin Med Assoc 2006, 69:146-152.

15. Picerno I, Di Pietro A, Spataro P, Di Benedetto A, Romano G, Scoglio ME: Is diabetes mellitus a risk factor for HCV infection? Ann Ig 2002, 14:473-477.

16. Balogun WO, Adeleye JO, Akinlade KS, Kuti M, Otegbayo JA: Low prevalence of hepatitis-C viral seropositivity among patients with type-2 diabetes mellitus in a tertiary hospital. J Natl Med Assoc 2006, 98:1805-1808.

17. Gulcan A, Gulcan E, Toker A, Bulut I, Akcan Y: Evaluation of risk factors and seroprevalence of hepatitis $B$ and $C$ in diabetic patients in Kutahya, Turkey. J Investig Med 2008, 56:858-863.

18. Konrad T, Zeuzem S, Vicini P, Toffolo G, Briem D, Lormann J, Herrmann G, Berger A, Kusterer K, Teuber G, Cobelli C, Usadel KH: Evaluation of factors controlling glucose tolerance in patients with $\mathrm{HCV}$ infection before and after 4 months therapy with interferon-a. Eur J Clin Invest 2000, 30(2):111-121.

19. Petit JM, Bour JM, Galland-Jos C, Minello A, Verges B, Guiguet M, Brun JM, Hillon P: Risk factors for diabetes mellitus and early insulin resistance in chronic hepatitis C. Hepatology 2001, 35:279-283.

20. Chen LK, Hwang SJ, Tsai ST, Luo JC, Lee SD, Chang FY: Glucose intolerance in Chinese patients with chronic hepatitis C. World I Gastroenterol 2003, 9:505-8.

21. Mehta SH, Brancati FL, Sulkowski MS, Strathdee SA, Szklo M, Thomas DL: Prevalence of type 2 diabetes mellitus among persons with hepatitis $C$ virus infection in the United States. Hepatology 2001, 33:1554.

22. Hamid S, Umar M, Alam A, Siddiqui A, Qureshi H, Butt J, Pakistan Society of Gastroenterology: PSG consensus statement on management of hepatitis C virus infection-2003. J Pak Med Assoc 2004, 54(3):146-50.

23. Shaw JE, Sicree RA, Zimmet PZ: Global estimates of the prevalence of diabetes for 2010 and 2030. Diabetes Res Clin Pract 2010, 87(1):4-14.

24. Negro F, Alaei M: Hepatitis C virus and type 2 diabetes. World J Gastroenterol 2009, 15(13):1537-1547.

25. Ndako JA, Echeonwu GO, Shidali NN, Bichi IA, Paul GA, Onovoh E, Okeke LA: Occurrence of hepatitis $C$ virus infection in type 2 diabetic patients attending Plateau state specialist hospital Jos Nigeria. Virol J 2009, 6:98.

26. Parolin MB, Réa R, Vargas RM, de Almeida AC, Baldanzi GR, Lopes RW: [Prevalence of hepatitis $C$ infection in patients with type 2 diabetes mellitus]. Article in Portuguese. Arq Gastroenterol 2006, 43(2):77-80.

27. Li-Ng M, Tropp S, Danoff A, Bini EJ: Association between chronic hepatitis $B$ virus infection and diabetes among Asian Americans and Pacific Islanders. Dig Liver Dis 2007, 39:549-556.

28. Mehta SH, Brancati FL, Strathdee SA, Pankow JS, Netski D, Coresh J, Szklo M, Thomas DL: Hepatitis C virus infection and incident type 2 diabetes. Hepatology 2003, 38:50-56.

29. Kaabia N, Ben Jazia E, Slim I, Fodha I, Hachfi W, Gaha R, Khalifa M, Hadj Kilani A, Trabelsi H, Abdelaziz A, Bahri F, Letaief A: Association of hepatitis C virus infection and diabetes in central Tunisia. World I Gastroenterol 2009, 15(22):2778-2781. 
30. Costa LM, Mussi AD, Brianeze MR, Souto FJ: Hepatitis $C$ as a risk factor for diabetes type 2: lack of evidence in a hospital in central-west Brazil. Braz J Infect Dis 2008, 12:24-26.

31. Ali SS, Ali IS, Aamir AH, Jadoon Z, Inayatullah S: Frequency of hepatitis $C$ infection in diabetic patients. J Ayub Med Coll Abbottabad 2007, 19(1):46-9.

32. Caronia S, Taylor K, Pagliaro L, Carr C, Palazzo U, Petrik J, O'Rahilly S,

Shore $\mathrm{S}$, Tom BD, Alexander GJ: Further evidence for an association between non-insulin-dependent diabetes mellitus and chronic hepatitis C virus infection. Hepatology 1999, 30:1059-1063.

doi:10.1186/1743-422X-7-304

Cite this article as: Jadoon et al:: Seroprevalence of hepatitis C in type 2 diabetes: evidence for a positive association. Virology Journal 2010 7:304.

\section{Submit your next manuscript to BioMed Central} and take full advantage of:

- Convenient online submission

- Thorough peer review

- No space constraints or color figure charges

- Immediate publication on acceptance

- Inclusion in PubMed, CAS, Scopus and Google Scholar

- Research which is freely available for redistribution

Submit your manuscript at www.biomedcentral.com/submit
C Biomed Central 